\title{
REVISIÓN DAS PRIMEIRAS EXPERIENCIAS DE RESINACIÓN EN GALICIA
}

(1950-1970)

Enrique MARTÍNEZ CHAMORRO

Centro de Investigación Forestal de Lourizán

Resumo: Neste artigo revísanse as experiencias de resinación desenvolvidas en Galicia dende a década dos 50 aos 60, baseándose en publicacións e no estudo de antigos documentos rescatados do Instituto Forestal de Investigacións e Experiencias (IFIE). Os documentos recompilados resumen as experiencias de investigación realizadas en Galicia, e aportan unhas primeiras conclusións que permiten discorrer sobre a viabilidade económica da extracción de resina en Galicia, e investigar sobre unha silvicultura que compatibilizase 0 aproveitamento principal da madeira coa extracción complementaria de resina do pino pinaster.

Palabras chave: sistemas resinación, pica con casca, silvicultura, Pinus pinaster Ait.

Title: Review of the first experiences of oleoresin production in Galicia (1950-1970)

Abstract: This paper reviews the first experiences in the production of oleoresin in Galicia (North Western Iberian Peninsula) during the second half of the 20th century. The study is based primarily on ancient documents rescued from the IFIE (Spanish Forest Research and Experiences Institute) that summarizes not only the trials established in Galicia, but provides information on the conclusions drawn to compatibilize timber and crude resin production, and analyze their economic viability.

Key words: resin gathering method, bark streak method, Pinus pinaster Ait. , North-West of the Iberian Peninsula, silviculture.

\section{INTRODUCIÓN}

O aproveitamento resineiro consiste na realización de incisións no tronco das árbores, que permiten a recollida da mera, materia prima empregada na industria resineira e que está constituída polo produto volátil (augarrás) e o corpo sólido de natureza vítrea que se obtén como residuo da destilación (colofonia). 0 aproveitamento da resina ou mera en España acadou a súa máxima expansión a principios de los anos 60 do século $\mathrm{XX}$, no que se totalizaron 270.000 ha resinadas (Serrada, 2004), acadando en España a súa máxima produción no ano 1961, con máis de 55.000 toneladas, e en Portugal no ano 1973 superando as 90.000 toneladas (Picardo, 2013).

O Pinus pinaster é a especie española do xénero Pinus que mellor se adapta ao aproveitamento resineiro, malia se resinaron tamén outras especies. Os piñeirais de maior produción resineira foron os da Meseta norte, nas provincias de Segovia, Ávila ou Valladolid, aínda que o aproveitamento afectou tamén a piñeirais da serra en Soria, Cuenca, León, Guadalaxara ou Albacete, malia que con producións máis modestas (Rodríguez Soalleiro et al, 2008). Os sistemas de resinación foron evolucionando ao longo do século XX, dende os que afectaban á madeira (albura), ata os que fixeron compatible o aproveitamento resineiro do piñeiro coa súa explotación da madeira.

Porén, a década dos oitenta marca o inicio dunha crise nas explotacións resineiras, tanto en España como Portugal, debido fundamentalmente á perda da cota de mercado:

enrique.martinez.chamorro@xunta.es . Centro de Investigación Forestal de Lourizán, c/ Marín Iglesia, 19 Lourizán 36153 Pontevedra.

Agradecementos: A D. Juan Carlos Álvarez, presidente da Mesa da Resina en Castela e León e da Asociación Nacional para a Defensa e Vertebración do Sector Resineiro, pola doazón da documentación inédita do IFIE que posuía, ao Centro de Investigación Forestal de Lourizán da Xunta de Galicia, esencial para poder realizar este artigo. 
elevados custos de produción, disminución da man de obra, e sobre todo, a entrada de China no mercado con prezos moi inferiores aos Europeos (Anastácio et al, 2008). Nembargantes, China actualmente baixou o ritmo das súas exportacións debido, fundamentalmente, á caída da produción nacional, motivada pola perda da man de obra no campo, ao incremento dos custos salariais, e as más prácticas e planificación dos seus aproveitamentos resineiros que deterioraron, en moitos casos, o seu patrimonio forestal (Picardo, 2013).

Tendo en conta este contexto, o rexurdir deste aproveitamento no Norte de Portugal (Santos, 2013) ou en Castela e León e as perspectivas e interese en Galicia, o obxectivo deste artigo é revisar os primeiros ensaios sobre sistemas de resinación realizados en Galicia, recompilando os resultados de producións obtidas e a definición dos métodos de resinación e técnicas máis axeitadas ás peculiaridades produtivas e estacionais dos piñeirais atlánticos.

\section{OS MÉTODOS DE RESINACIÓN ENSAIADOS EN GALICIA}

Dende 1940 ata 1970 inciáronse na península ibérica ensaios e experiencias de resinación con diferentes sistemas (Radich, 1995; Hernández, 2006). En España, foi o Instituto Forestal de Investigacións e Experiencias (IFIE) a través da súa sección de resinas e produtos derivados o que promoveu varias probas con diferentes sistemas de resinación.

A comezos dos anos 50 o antiguo IFIE en colaboración cos servizos forestais provinciais, e especialmente co Distrito Forestal de Pontevedra, realizou experiencias sobre resinación en Galicia que se alongaron ata principios dos anos 70. Galicia, malia non ser unha rexión tradicionalmente resineira, captou deseguido o interese de industriais e da propia administración, debido ás extensas masas de Pinus pinaster existentes, e á necesidad de impulsar a produción de resina fora das rexións tradicionalmente resineiras do centro peninsular.

Dos ensaios e experiencias que se amosan neste artigo, dedúcese que en Galicia se empregaron polo menos 4 sistemas de resinación:

a. o sistema Hugues, tradicionalmente aplicado dende o S.XIX, no que se realizaba unha incisión ou ferida vertical e alongada na superficie descascada do tronco, consistente en arrincar de arriba abaixo unhas poucas estelas ou lascas, ata penetrar na albura $1,5 \mathrm{~cm}$ de profundidade máxima, deixando na superficie do tronco unha cara cóncava con perda de madeira. (Calderón, A. 2009; Hernández, 2006). (foto 1)

b. o sistema Mazek de "espiña de peixe", consiste en realizar cun cepillo do mesmo nome, unha serie de estrías longas e transversais ou canais en forma de $\mathrm{V}$, incisións que forman un ángulo de $45^{\circ}$ co eixe da árbore e que permiten que a mera se deslice facilitando así a súa recollida (Najera et al., 1957; Solís, 1968). (foto 2)

c. o sistema de caras múltiples, onde se realizaban picas ${ }^{1}$ longas e continuas de $10 \mathrm{~mm}$ de ancho ao longo do eixe da árbore, e en número de 5. Aquí a cicatrización é moi rápida, así que se poden volver explotar as caras que se reconstitúen (Calderón, A. 2009). (foto 3)

d. o sistema americano de "pica con casca" consiste na realización das picas ou incisións de forma transversal cunha aixola ou cotazo e a aplicación dun estimulante ácido, sempre antes de descascar o piñeiro (Pinillos et al., 2004). (foto 4).

1 Picas: Incisións que se realizan sobre un piñeiro para obter a resina. 
Foto 1. Resinación no Pinhal do Rei. Marinha Grande (Portugal) por método Hugues ou francés.

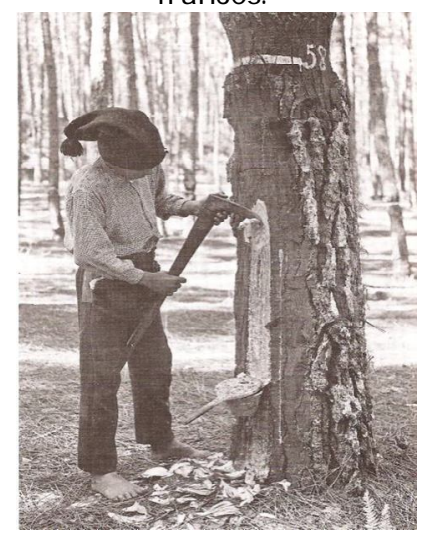

Fonte: A exposição "Factos e Personalidades do Pinhal do Rei". 2011

Foto 2. Resinación polo sistema Mazek el Alijar. As Navas do Marqués (Ávila)

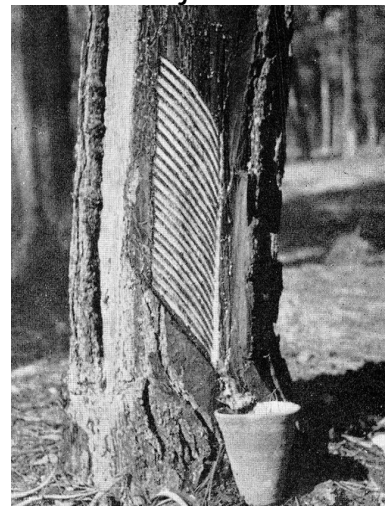

Fonte: Fototeca forestal. INIA

Foto 3. Parcela de investigación. Ensaio de extracción polo método español de "caras múltiples”. Localización probable: península do Morrazo (Pontevedra).

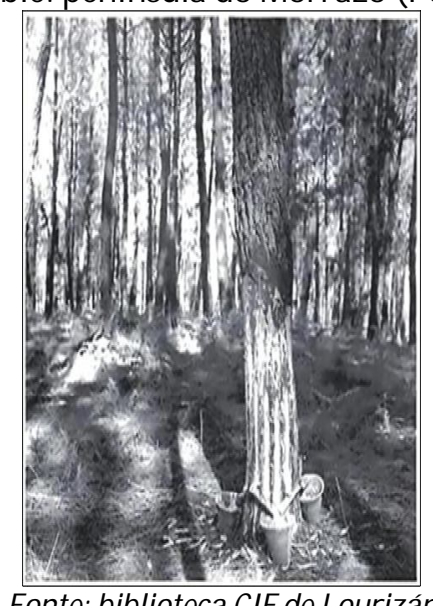

Fonte: biblioteca CIF de Lourizán 
Foto 4. Sistema americano de resinación de Pica de Casca; talladura estimulada con ácido sulfúrico.

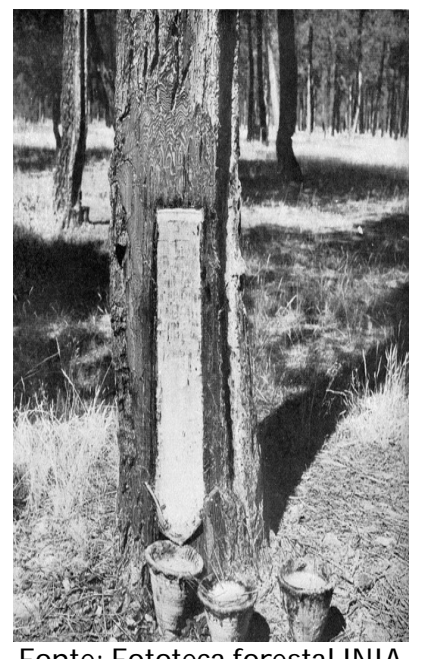

Fonte: Fototeca forestal INIA

En 1952 o IFIE iniciou en Coca (Segovia) experiencias co daquela novidoso sistema de resinación de pica de casca, que consistiu en primeiro lugar na adaptación do sistema e comprobación dos seus rendementos en produción de mera. Despois veu unha segunda fase de extensión do ensaio a todo o ámbito nacional, comparando o novo sistema de pica de casca con estimulación e as súas variantes co sistema Hugues, sobre máis de 200.000 piñeiros de distintas especies das que destacan o Pinus pinaster Ait., o Pinus halepensis Mill. e o Pinus nigra Arnold. Comprobouse unha mellora dos tempos de extracción, unha maior facilidade de aprendizaxe e un incremento de produción de mera de máis do 10\% (Anales IFIE 1965).

\section{EXPERIENCIAS DOS ANOS 50: ENSAIO DE MÉTODOS E PRODUCIÓNS}

As primeiras experiencias das que se teñen constancia en Galicia son dos anos 1952-1953, e consistiron en probar o sistema Mazek, que tiña como principal vantaxe o seu menor consumo de madeira e a súa maior facilidade de aprendizaxe, malia ser menos produtivo có sistema Hugues (Najera et al, 1957). Escolléronse, na península do Morrazo, dúas rodeiras destinadas a ser cortadas ao rematar as dúas campañas de resinación que tiñan previsto, motivo polo que se abriron todas as caras que o diámetro das árbores $(23 \mathrm{~cm}$ como media) permitía. Consideráronse dous factores: o número de talladuras a abrir (2 ou 3) e a estimulación química, con e sen aplicación de ácido sulfúrico ao 50\%.

Abríronse polo tanto dúas ou tres talladuras ${ }^{2}$ sobre outras tantas caras de $12 \mathrm{~cm}$ de anchura, tomando como referencia árbores resinadas co método Hugues tamén con dúas ou tres talladuras. No caso da resinación Mazek ensaiouse a estimulación química con $\mathrm{SO}_{4} \mathrm{H}_{2}$ ao $50 \%$, cos resultados que se amosan na Táboa 1, onde se aprecia unha redución da produción do 37 ao 50\% en Mazek con respecto a Hugues cando non se aplica estimulación, malia que as reducións en produción son menores cando o sistema Mazek se combina con estimulación (do 10 ao $44 \%$ inferior). A abertura simultánea de tres talladuras supón que o efecto da estimulación química resulta menos importante. Estes

2 Talladura: Conxunto de picas feitas sobre un mesmo tronco e unidas entre si consecutivamente ao longo da campaña 
resultados, segundo os autores, débense á falta de coñecementos da man de obra e ao escaso diámetro das árbores.

Táboa 1. Sistema MAZEK normal con talladura de $12 \mathrm{~cm}$. Lugar de ensaio O Morrazo (Pontevedra).

\begin{tabular}{|c|c|c|c|c|c|c|c|c|c|c|c|c|}
\hline \multirow{3}{*}{$\begin{array}{c}\text { Campañ } \\
\text { a }\end{array}$} & \multicolumn{6}{|c|}{ PIÑEIROS CON DÚAS TALLADURAS } & \multicolumn{6}{|c|}{ PIÑEIROS CONTRES TALLADURAS } \\
\hline & \multirow{2}{*}{$\begin{array}{l}\text { № } \\
\text { de } \\
\text { piñe } \\
\text { iros }\end{array}$} & \multirow{2}{*}{$\begin{array}{c}\text { № } \\
\text { de } \\
\text { pica } \\
\text { s }\end{array}$} & \multirow{2}{*}{$\begin{array}{l}\text { Tempo } \\
\text { en días }\end{array}$} & \multicolumn{2}{|c|}{$\begin{array}{l}\text { Produción por } \\
\text { piñeiro (kg) }\end{array}$} & \multirow{2}{*}{$\begin{array}{c}\% \\
\text { sobre } \\
\text { Hugue } \\
\text { s }\end{array}$} & \multirow{2}{*}{$\begin{array}{l}\text { № } \\
\text { de } \\
\text { piñe } \\
\text { iros }\end{array}$} & \multirow{2}{*}{$\begin{array}{c}\text { № } \\
\text { de } \\
\text { pica } \\
\text { S }\end{array}$} & \multirow{2}{*}{$\begin{array}{l}\text { Tempo } \\
\text { en días }\end{array}$} & \multicolumn{2}{|c|}{$\begin{array}{l}\text { Produción por } \\
\text { piñeiro (kg) }\end{array}$} & \multirow{2}{*}{$\begin{array}{c}\% \\
\text { sobre } \\
\text { Hugue } \\
\text { s }\end{array}$} \\
\hline & & & & $\begin{array}{l}\text { Hugu } \\
\text { es }\end{array}$ & $\begin{array}{l}\text { Maz } \\
\text { ek }\end{array}$ & & & & & $\begin{array}{l}\text { Hugue } \\
\text { s }\end{array}$ & $\begin{array}{c}\text { Maze } \\
\mathrm{k}\end{array}$ & \\
\hline 1952 & 148 & 39 & 228 & 2,795 & 1,759 & $-37,06$ & 147 & 39 & 228 & 4,25 & 2,166 & $-49,03$ \\
\hline 1953 & 146 & 35 & 212 & 2,31 & 1,414 & $-38,78$ & 146 & 35 & 212 & 3,07 & 1,76 & $-42,67$ \\
\hline
\end{tabular}

Sistema MAZEK estimulado con $\mathrm{SO}_{4} \mathrm{H}_{2}$ ao $50 \%$ e talladura de $12 \mathrm{~cm}$. Lugar de ensaio O Morrazo.

\begin{tabular}{|c|c|c|c|c|c|c|c|c|c|c|c|c|}
\hline \multirow{3}{*}{$\begin{array}{c}\text { Campañ } \\
\text { a }\end{array}$} & \multicolumn{6}{|c|}{ PIÑEIROS CON DÚAS TALLADURAS } & \multicolumn{6}{|c|}{ PIÑEIROS CONTRES TALLADURAS } \\
\hline & \multirow{2}{*}{$\begin{array}{c}\text { № } \\
\text { de } \\
\text { piñe } \\
\text { iros }\end{array}$} & \multirow{2}{*}{$\begin{array}{c}\text { № } \\
\text { de } \\
\text { pica } \\
\text { s }\end{array}$} & \multirow{2}{*}{$\begin{array}{l}\text { Tempo } \\
\text { en días }\end{array}$} & \multicolumn{2}{|c|}{$\begin{array}{l}\text { Produción por } \\
\text { piñeiro }(\mathrm{kg})\end{array}$} & \multirow{2}{*}{$\begin{array}{c}\% \\
\text { sobre } \\
\text { Hugue } \\
\text { s }\end{array}$} & \multirow{2}{*}{$\begin{array}{c}\text { № } \\
\text { de } \\
\text { piñe } \\
\text { iros }\end{array}$} & \multirow{2}{*}{$\begin{array}{c}\text { № } \\
\text { de } \\
\text { pica } \\
\text { S }\end{array}$} & \multirow{2}{*}{$\begin{array}{l}\text { Tempo } \\
\text { en días }\end{array}$} & \multicolumn{2}{|c|}{$\begin{array}{l}\text { Produción por } \\
\text { piñeiro (kg) }\end{array}$} & \multirow{2}{*}{$\begin{array}{l}\text { \% sobre } \\
\text { Hugues }\end{array}$} \\
\hline & & & & $\begin{array}{l}\text { Hugu } \\
\text { es }\end{array}$ & $\begin{array}{c}\text { Maz } \\
\text { ek }\end{array}$ & & & & & $\begin{array}{l}\text { Hugue } \\
\text { s }\end{array}$ & Mazek & \\
\hline 1952 & 149 & 39 & 228 & 2,795 & 2,515 & $-10,01$ & 150 & 39 & 228 & 4,25 & 2,363 & $-44,4$ \\
\hline 1953 & 147 & 35 & 212 & 2,31 & 2,05 & $-11,25$ & 148 & 35 & 212 & 3,07 & 2,35 & $-23,44$ \\
\hline
\end{tabular}

A segunda experiencia realizouse con caras $^{3}$ de igual anchura có diámetro do piñeiro, empregando o sistema Mazek sen estimulación e con estimulación de $\mathrm{SO}_{4} \mathrm{H}_{2}$, pero neste caso con concentracións ao $30 \%$, ao $40 \%$ e ao $50 \%$, na Táboa 2, á parte de observarse resultados semellantes aos da Táboa 1, non se constata tampouco diferenzas de produción entre as porcentaxes de ácido sulfúrico empregadas. Igual ca no caso anterior, os autores, poñen de manifesto que os diámetros normais e a habilidade dos resineiros eran baixos.

Dentro desta fase de extensión do ensaio proposta pola sección de resinas, probablemente no ano 1954-55, déronse as segundas experiencias de resinación en Galicia, tamén na península do Morrazo (Pontevedra). Tratábase de probar distintos sistemas de resinación, con e sen estimulación química abrindo tres clases de caras de resinación: de $12 \mathrm{~cm}$, de anchura igual ao diámetro normal do piñeiro e abrindo caras en toda a árbore (Nájera, 1956). Empregáronse, á parte do anterior sistema dous novos sistemas de resinación:

a. o sistema americano de "pica con cascas" empregando resinación normal e estimulada con $\mathrm{SO}_{4} \mathrm{H}_{2}$ en concentracións de 30-40-50\%, nas tres clases descritas, sistema que tamén se aplicou ao Pinus radiata D. Don con ácido ao $40 \%$.

b. o sistema "caras múltiples" aplicado ao Pinus pinaster Ait. e ao Pinus radiata D. Don con unha ou dúas caras de $12 \mathrm{~cm}$ para o primeiro e unha soa de $12 \mathrm{~cm}$. para 0 segundo.

Nesta segunda experiencia, volveu quedar limitada polo delgada que era a masa, aínda que se concluíu que os redementos foron superiores aos do sistema Hugues, nos casos nos que se empregaba $\mathrm{SO}_{4} \mathrm{H}_{2}$ como estimulante.

${ }^{3}$ Cara: conxunto de talladuras que se fan nun piñeiro 
Durante esta segunda experiencia ampliada agora no tempo (1957) e no espazo, empregáronse en Galicia os tres sistemas de resinación comentados e o sistema Hugues como referencia, e concluíse que o que reunía mellores condicións para o pino pinaster de Galicia era o citado americano de pica de casca estimulado con ácido sulfúrico ao 30-40\%.

Resulta relevante tamén do informe de 1957, no que se constata unha ampliación da experiencia a diferentes localizacións do sur de Galicia: Tomiño, Pontareas e Entrimo (foto 6) e no que, aínda descartando o sistema Hugues, se fai un estudo de produción comparada con este sistema, utilizando árbores de máis de $30 \mathrm{~cm}$ de diámetro normal e obtendo unha media de 2,76 kg durante os catro anos de experiencias.

Táboa 2. Resinación intensiva: Sistema MAZEK cunha talladura ao seu diámetro: HUGUES dúas talladuras - Lugar de ensaio: O Morrazo (Pontevedra)

\begin{tabular}{|c|c|c|c|c|c|c|c|c|c|c|c|c|c|c|c|}
\hline \multirow[t]{2}{*}{ ENSAIO } & \multicolumn{5}{|c|}{1953} & \multicolumn{5}{|c|}{1954} & \multicolumn{5}{|c|}{1955} \\
\hline & $\begin{array}{l}\text { № } \\
\text { de } \\
\text { piñ } \\
\text { eir } \\
\text { os }\end{array}$ & $\begin{array}{c}\text { № } \\
\text { de } \\
\text { pic } \\
\text { as }\end{array}$ & $\begin{array}{c}\text { dí } \\
\mathrm{a} \\
\mathrm{s}\end{array}$ & $\begin{array}{l}\text { Pr } \\
\text { od. } \\
\mathrm{kg}\end{array}$ & $\begin{array}{c}\% \\
\text { respe } \\
\text { cto } \\
\text { Hugu } \\
\text { es }\end{array}$ & $\begin{array}{l}\text { № } \\
\text { de } \\
\text { piñ } \\
\text { eir } \\
\text { os }\end{array}$ & $\begin{array}{l}\text { № } \\
\text { de } \\
\text { pic } \\
\text { as }\end{array}$ & $\begin{array}{l}\text { dí } \\
\text { a } \\
\text { s }\end{array}$ & $\begin{array}{l}\text { Pr } \\
\text { od. } \\
\mathrm{kg}\end{array}$ & $\begin{array}{c}\% \\
\text { respe } \\
\text { cto } \\
\text { Hugu } \\
\text { es }\end{array}$ & $\begin{array}{l}\text { № } \\
\text { de } \\
\text { piñ } \\
\text { eir } \\
\text { os }\end{array}$ & $\begin{array}{l}\mathrm{N} \\
\underline{\mathrm{o}} \\
\mathrm{d} \\
\mathrm{e} \\
\mathrm{p} \\
\mathrm{i} \\
\mathrm{c} \\
\mathrm{a} \\
\mathrm{s}\end{array}$ & $\begin{array}{c}\text { día } \\
\text { s }\end{array}$ & $\begin{array}{l}\mathrm{Pr} \\
\text { od } \\
\mathrm{kg} .\end{array}$ & $\begin{array}{c}\% \\
\text { respe } \\
\text { cto } \\
\text { Hugu } \\
\text { es }\end{array}$ \\
\hline $\begin{array}{l}\text { Sistema } \\
\text { Hugues }\end{array}$ & $\begin{array}{l}1 \\
0 \\
0\end{array}$ & 34 & $\begin{array}{l}1 \\
7 \\
2\end{array}$ & $\begin{array}{c}2,3 \\
1\end{array}$ & & $\begin{array}{c}10 \\
0\end{array}$ & 36 & $\begin{array}{l}2 \\
1 \\
0\end{array}$ & $\begin{array}{l}2,9 \\
08\end{array}$ & & $\begin{array}{c}10 \\
0\end{array}$ & 39 & $\begin{array}{l}2 \\
3 \\
0\end{array}$ & $\begin{array}{l}3,9 \\
34\end{array}$ & \\
\hline $\begin{array}{l}\text { MAZEK } \\
\text { normal }\end{array}$ & $\begin{array}{l}5 \\
0\end{array}$ & 34 & $\begin{array}{l}1 \\
7 \\
2\end{array}$ & $\begin{array}{l}1,4 \\
55\end{array}$ & $-37,1$ & 49 & 36 & $\begin{array}{l}2 \\
1 \\
0\end{array}$ & $\begin{array}{l}2,0 \\
67\end{array}$ & 28,98 & 44 & 39 & $\begin{array}{l}2 \\
3 \\
0\end{array}$ & $\begin{array}{l}2,1 \\
98\end{array}$ & $\begin{array}{c}- \\
44,12\end{array}$ \\
\hline $\begin{array}{c}\text { MAZEK } \\
\text { estimul } \\
\text { ado }\end{array}$ & & & & & & & & & & & & & & & \\
\hline $\begin{array}{r}\mathrm{SO}_{4} \mathrm{H}_{2} \\
\text { ao30\% }\end{array}$ & $\begin{array}{l}5 \\
0\end{array}$ & 34 & $\begin{array}{l}1 \\
7 \\
2\end{array}$ & $\begin{array}{l}1,9 \\
05\end{array}$ & 17,53 & 49 & 36 & $\begin{array}{l}2 \\
1 \\
0\end{array}$ & $\begin{array}{l}2,4 \\
15\end{array}$ & 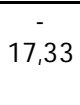 & 43 & 39 & $\begin{array}{l}2 \\
3 \\
0\end{array}$ & $\begin{array}{l}2,4 \\
58\end{array}$ & $\begin{array}{c}- \\
37,52\end{array}$ \\
\hline $\begin{array}{c}\mathrm{SO}_{4} \mathrm{H}_{2} \\
\text { ao } 40 \%\end{array}$ & $\begin{array}{l}5 \\
0\end{array}$ & 34 & $\begin{array}{l}1 \\
7 \\
2\end{array}$ & $\begin{array}{l}2,0 \\
75\end{array}$ & 10,21 & 49 & 36 & $\begin{array}{l}2 \\
1 \\
0\end{array}$ & $\begin{array}{l}2,5 \\
38\end{array}$ & 12,72 & 43 & 39 & $\begin{array}{l}2 \\
3 \\
0\end{array}$ & $\begin{array}{l}2,3 \\
37\end{array}$ & $\begin{array}{c}- \\
39,57\end{array}$ \\
\hline $\begin{array}{c}\mathrm{SO}_{4} \mathrm{H}_{2} \\
\text { ao } 50 \%\end{array}$ & $\begin{array}{l}5 \\
0\end{array}$ & 34 & $\begin{array}{l}1 \\
7 \\
2\end{array}$ & $\begin{array}{c}1,9 \\
4\end{array}$ & $\begin{array}{c}- \\
16,01\end{array}$ & 49 & 36 & $\begin{array}{l}2 \\
1 \\
0\end{array}$ & $\begin{array}{c}2,7 \\
2\end{array}$ & $-6,46$ & 43 & 39 & $\begin{array}{l}2 \\
3 \\
0\end{array}$ & $\begin{array}{c}2,6 \\
2\end{array}$ & $-33,4$ \\
\hline
\end{tabular}

Tamén existe constancia dunha segunda experiencia da Deputación de Pontevedra en piñeirais repoboados na península do Morrazo (Pontevedra) con diámetros entre os $22 \mathrm{e}$ $23 \mathrm{~cm}$ e onde a produción de mera polo método Hugues en caras de $12 \mathrm{~cm}$ foi de 2,25 Kg de media.

Na Táboa 3 amósase a media dos resultados obtidos durante 4 anos con este sistema en lugares de ensaio con resinacións a vida e a morte $^{5}$ con dous dimensións de cara, un feito destacable é o tema de establecer caras estreitas de $9 \mathrm{~cm}$ de anchura co método Hugues, de gran importancia en Galicia para que a madeira se depreciara o menos posible.

${ }^{4}$ Resinación a vida: mantense aberta unha única cara en cada momento

${ }^{5}$ Resinación a morte cando se lle abren simultaneamente todas as caras posibles. 
Táboa 3. Producións (kg/árbore) nas experiencias realizadas en Galicia na década dos 50 co método Hugues.

\begin{tabular}{|c|c|c|c|c|}
\hline Clase de resinación & \multicolumn{2}{|c|}{ A vida } & \multicolumn{2}{c|}{ A morte } \\
\hline Lugar de ensaio & caras de $9 \mathrm{~cm}$ & caras de $12 \mathrm{~cm}$ & caras de $9 \mathrm{~cm}$ & caras de $12 \mathrm{~cm}$ \\
\hline Tomiño & 2,0 & 2,2 & 3,6 & 3,8 \\
\hline Ponteareas & 2,9 & 3,2 & 3,7 & 5,5 \\
\hline Entrimo & 2,7 & 2,8 & 3,3 & 3,6 \\
\hline $\begin{array}{c}\text { produción } \\
\text { Media }(\mathrm{kg})\end{array}$ & $\mathbf{2 , 5 6}$ & $\mathbf{2 , 7 6}$ & $\mathbf{2 , 4 5}$ & $\mathbf{4 , 3 6}$ \\
\hline
\end{tabular}

Analizando estes datos de produción en vida con caras de $12 \mathrm{~cm}$, o informe deduce que son valores practicamente iguais aos valores medios españois en resinación que oscilan entre os 1,9 kg de Teruel e Málaga e os 4 kg de Segovia.

O informe establece dous requisitos ou condicións que considera básicas e que debe cumprir o método de resinación que se aplique en Galicia:

a. ser compatible co actual aproveitamento madeirable, no senso de non perturbar o volume de madeira que anualmente se corta

b. que o seu manexo sexa cómodo e de aprendizaxe fácil e rápida

Continúa o informe indicando que a mera galega ten unha cantidade de agua e impurezas sólidas superior á do resto de rexións resineiras o que rebaixara o grao de colofonia ${ }^{6}$ obtida.

Finalmente, o informe conclúe que o sistema de pica de casca con estimulación, sen dúbida, dará unha produción superior ao do sistema Hugues. E prognostica unha primeira estimación da produción de mera de $3,5 \mathrm{~kg} /$ piñeiro partindo do feito de que a cada piñeiro se lle poidan abrir dúas caras opostas nos dous anos anteriores á súa corta. $\mathrm{O}$ autor basea este prognóstico en que anualmente se estaban cortando para serra 3,3 millóns de piñeiros, realizando o seguinte cálculo sobre a produción teórica posible de mera en Galicia:

3,3M de piñeiros $\mathrm{x} 2$ anos $\times 3,5 \mathrm{~kg} /$ anos $=23.100 \mathrm{~T}$

O que suporía arredor do 50\% da produción nacional, que era de $43.000 \mathrm{~T}$

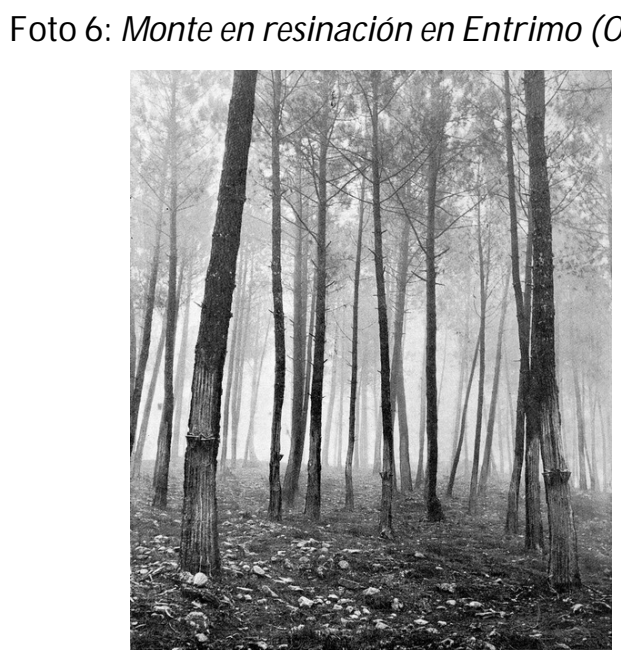

Fonte: fototeca forestal. INIA

${ }^{6}$ Colofonia: é o corpo sólido de natureza vítrea que se obtén como residuo da destilación da mera. 


\section{EXPERIENCIAS DOS ANOS 60: CONDICIÓNS DO APROVEITAMENTO E COMPATIBILIDADE COA MADEIRA}

Outro informe elaborado pola Sección de resinas no ano 1961 titulado: "Informe sobre a resinación dos piñeirais de Galicia e condicións xerais que se propoñen para 0 outorgamento deste aproveitamento" cuxo autor é Fernando Nájera y Angulo coa colaboración de Rafael Boulet Sirvent, analiza dende as condicións que debe reunir a resinación en Galicia ata as bases para o outorgamento do aproveitamento dos piñeirais de Galicia establecendo as directrices dun plan quinquenal (1963/ 67).

Do informe cabe destacar que matiza as dúas condicións, xa mencionadas no informe de 1957, en canto ás condicións que deben reunir o sistema de resinación que se utilice en Galicia, e inclúe outras novas:

a. a resinación debe ser un aproveitamento secundario fronte á madeira polo que se debe propugnar que o turno de resinación abranga como máximo os cinco anos, inmediatamente anteriores á corta do piñeiro

b. deberanse realizar caras de resinación que non afecten moito ao crecemento en diámetro, nin ao rendemento en madeira serrada

c. o minifundismo da propiedade forestal fai imposible a resinación con obreiros contratados para traballar un determinado número de piñeiros, polo que só cabe a resinación de fincas ou rodeiros que cumpran as condicións de turnos das parcelas

Especial interese ten o informe á hora de formular solucións no contexto de Galicia tendentes a mellorar as cantidades de mera recollida. Segundo os autores, as cantidades recollidas son dun 20 a un $25 \%$ menor cas producidas debido ao derrame de parte da mera que se obtén pola choiva. Sobre este problema, formúlanse solucións que van dende o aumento da capacidade dos potes nun 50\% (potes con diámetros exteriores de 80 a 170 $\mathrm{mm}$ e alturas de $140 \mathrm{~mm}$ ), ata o emprego de tampas. Ámbalas dúas actuacións permitirían, por unha banda, retrasar o enchido do pote a consecuencia das abundantes pluviometrías de Galicia, permitindo aos resineiros gañar tempo para o seu vaciado; e coas tampas, evitar a evaporación da augarrás e a caída de impurezas. Conclúen que con estas melloras no sistema de recolleita da mera, aumentaría en máis dun $10 \%$ o rendemento por piñeiro.

Como resultado final os investigadores propoñían como sistema óptimo para os piñeirais galegos o de pica de casca con estimulación a base de ácido sulfúrico ao 40-50\%.

Esta experiencia conclúe que a cifra de $2 \mathrm{~kg}$ por talladura, podería servir de base, con carácter mínimo, para o cálculo da capacidade resineira dos piñeirais en Galicia, compostos daquela maioritariamente por masas cunha espesura excesiva con árbores case todas de 20 a $25 \mathrm{~cm}$.

O resto do informe adícase a establecer as bases para aproveitamentos quinquenais dos piñeirais de Galicia: a posibilidade anual de produción de mera en función das existencias, as medadas e condicións descritas, a análise da capacidade de consumo de produtos resinosos en Galicia e, as posibilidades de exportación destes produtos, analizando tamén a viabilidade de construír dúas fábricas de destilación en Galicia. Concluíndo que, namentres non se determinen as condicións que debe reunir a resinación en Galicia por parte da Dirección Xeral de Montes, non se aconsella a construción de fábricas de destilación.

Por outra banda, tamén se reflicte a experiencia realizada pola Deputación de Pontevedra sobre 20.000 piñeiros nos montes do Morrazo. Esta experiencia cítase en: "o Informe sobre as experiencias de produción de mera polo sistema de resinación de pica con casca 
de 1962 da Sección de resinas e derivados (Anais do IFIE, 1962)" onde se desprende que se continuaron 5 anos máis cos ensaios do sistema de pica con casca cos resultados que se observan na Táboa 4.

Na experiencia determínase que o período de resinación anual foi de aproximadamente 7 meses, moi semellante ou ata algo superior ás das outras experiencias realizadas no centro da península ibérica, que o número de picas foi semellante ao resto; e que as producións foron algo máis baixas, tendo en conta que os ensaios se realizaron en quendas curtas e en árbores de diámetros pequenos $(20-25 \mathrm{~cm}$ de $\mathrm{DN})$ que ían a ser cortadas no prazo dun a tres anos. O informe conclúe: “...ao final do ano 1961 suspendéronse xa estes ensaios, por quedar suficientemente estudada e probada a posibilidade de resinación en Galicia”...

Táboa 4. Resumo das experiencias de produción de mera co sistema de pica con casca no Morrazo (Pontevedra)

\begin{tabular}{|c|c|c|c|c|c|}
\hline Año & № de piñeiros & Días & Picas & Talladuras & Prod. Media.(kg) \\
\hline 1957 & 14.750 & 209 & 29 & $1^{\mathrm{a}}$ & 2,040 \\
\hline \multirow{2}{*}{1958} & 14.750 & \multirow{2}{*}{216} & \multirow{2}{*}{29} & $2^{a}$ & \multirow{2}{*}{1,808} \\
\hline & 11.950 & & & $1^{\underline{a}}$ & \\
\hline \multirow[b]{2}{*}{1959} & 15.000 & \multirow[b]{2}{*}{229} & \multirow[b]{2}{*}{29} & $1^{\underline{a}}$ & \multirow[b]{2}{*}{1,931} \\
\hline & 11.000 & & & $2^{a^{a}}$ & \\
\hline \multirow[b]{2}{*}{1960} & 15.000 & \multirow[b]{2}{*}{220} & \multirow[b]{2}{*}{29} & $1^{\underline{a}}$ & \multirow[b]{2}{*}{1,916} \\
\hline & 11.000 & & & 3 a & \\
\hline 1961 & 22.000 & 217 & 28 & $1^{\mathrm{a}-}-2^{\mathrm{a}}-3^{\mathrm{a}}$ & 2,228 \\
\hline
\end{tabular}

Porén, a intención do IFIE con estas experiencias era obter a máxima información posible sobre o sistema de resinación idóneo que debía instaurarse nos piñeirais galegos e que se estaban realizando de forma semellante noutras parcelas do resto de España, sen estudar os efectos da perda de volume.

García Borregón (1966) xa indicaba a necesidade de coñecer cales son as verdadeiras perdas de crecemento anual que a aplicación da resinación produce na madeira dos piñeiros. A súa preocupación é lóxica xa que, segundo manifiesta, o prezo medio da madeira en pé en 1966 para árbores de 20 a $39 \mathrm{~cm}$ era de $800 \mathrm{ptas} / \mathrm{m}^{3} \mathrm{cc} .\left(4,808 € / \mathrm{m}^{3} \mathrm{cc}\right)$ valor que actualizado suporía $121,02 € / \mathrm{m}^{3} \mathrm{cc}^{7}$.

Moi probablemente, a importancia da madeira como recurso xa fora posta de manifesto en anteriores informes, xunto ao seu prezo, o que fixo que o IFIE en 1967 iniciara un "estudo relativo á influencia que exerce a resinación, polo sistema de pica con casca con estimulación, no crecemento madeirable", perante a falta de coñecementos sobre a influencia deste sistema no crecemento madeirable, as características físicas, químicas e mecánicas da madeira na industria do serrado.

Con este obxectivo, elixiuse o monte Seixos Albos de Tui, ao considerarse un lugar representativo dos piñeirais de Galicia con capacidade para ser resinados: diámetros normais de 20 a $40 \mathrm{~cm}$ e alta densidade. Durante o período de 1967 a 1971 reformulouse neste monte unha parcela onde resinaron, en principio, 100 piñeiros e deixáronse un

${ }^{7}$ O Instituto Nacional de Estatística (Actualización de rendas co IPC xeral (sistema IPC base 2011) para períodos anuais completos) 
número igual de pés de referencia sen resinar, elixidos todos eles por procedementos estatísticos.

Realizouse unha cubicación inicial pé a pé, no momento de instalar a parcela, para comenzar a realizar a resinación polo sistema de pica con casca con estimulante líquido, e comparar as medicións con outros 100 de referencia aos 3 e aos 5 anos, cumprindo dúas premisas:

1. O período de resinación debería ser os 5 anos anteriores á corta

2. Os piñeiros deberían ter máis de $20 \mathrm{~cm}$ de diámetro normal.

A experiencia reforzouse en 1969 engadindo unha segunda parcela con 54 piñeiros máis divididos en dous grupos de 27 para coñecer as posibilidades de resinación con pasta ${ }^{8}$ fronte aos estimulados con ácido sulfúrico ao $40 \%$. na foto $\mathrm{n}-5$ aprécianse árbores resinadas mediante o sistema de pica con casca sobre cara ancha fronte a outras de referencia sen resinar.

Foto 5: Ensaio de extracción de resina polo sistema de pica de casca con cara ancha. Localización probable: monte Seixos Albos (Tui. Pontevedra).

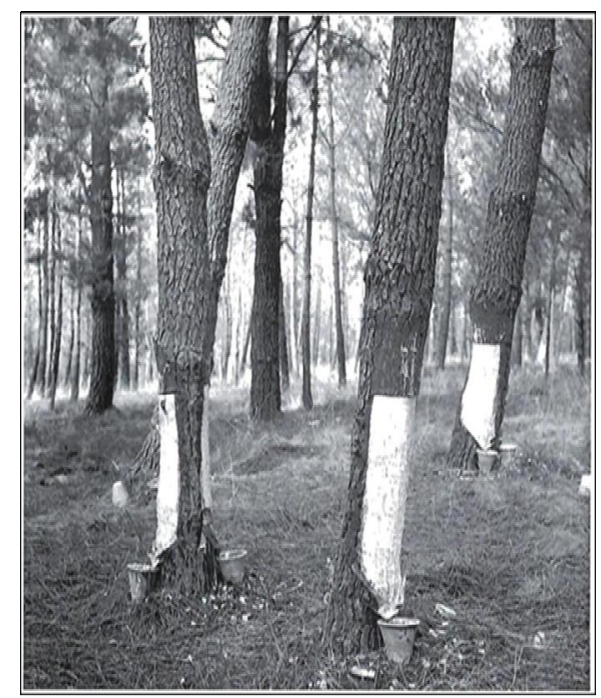

Fonte: Biblioteca CIF de Lourizán

Malia que non se puido atopar ningunha publicación ou informe sobre a experiencia, nun documento de 1970 resúmese brevemente o estado da experiencia que, segundo se aprecia na Táboa 5, acadouse unha media de produción aos 3 anos na parcela estimulada con ácido líquido de 3,1 kg e na parcela de 1969 (pasta fronte a fronte a ácido sulfúrico ao $40 \%$ líquido) diferenzas pouco significativas ao ter quizabes unha soa talladura.

Dos documentos estudados nada se desprende sobre o control de perda de crecemento en madeira, nin tampouco se atopou ningunha publicación dos resultados, porén, D. Miguel de Gaviña Mugica responsable da sección de resinas e produtos derivados do IFIE en outubro de 1966 nunha carta dirixida ao Xefe do Distrito de Pontevedra D. Ricardo García-Borregón estima que as posibles perdas serían inferiores ao 19\% do crecemento

\footnotetext{
8 Pasta: masa consistente nunha solución acuosa de ácido sulfúrico máis caolín e cloruro cálcico (Blanco A., 2011)
} 
corrente anual (CCA) a partir do momento que comece a resinación, sempre que se leve a cabo como máximo os 5 anos precedentes ao apeo por corta final.

Táboa 5. Datos aos 3 anos da experiencia de resinación mediante o sistema de pica con casca con estimulante líquido e pasta en "Seixos Albos". Tuy (Pontevedra).

\begin{tabular}{|c|c|c|c|}
\hline & Parcela de 1967 & \multicolumn{2}{|c|}{ Parcela de 1969} \\
\hline Tipo de estimulante & Ácido & Ácido & Pasta \\
\hline Talladura 1ํ. Año 1967 & 2,756 & & \\
\hline Talladura $2^{\circ}$. Año 1968 & 2,931 & & \\
\hline Talladura 3o. Año 1969 & 3,620 & & \\
\hline Talladura 1ํ. Año 1969 & - & 2,388 & 2,037 \\
\hline produción media en Kg: & 3,102 & & \\
\hline
\end{tabular}

Este tema de capital importancia para o caso dunha resinación complementaria ao aproveitamento madeireiro, foi algo máis estudado en Portugal, onde se iniciaron ensaios, na década dos cincuenta para determinar o decrecemento do diámetro normal na Mata Nacional de Leiria (Gomes,1954). Ultimamente, e baseado nunha hipótese teórica, Guardia, no $1^{\text {o }}$ Simposio de Aproveitamento de Resinas Naturais celebrado en Segovia, considera que a redución anual na produción de madeira é do 10\% (Guardia N., 1998), tomando como referencia o estudo de Figueiredo sobre a análise de árbores de Pinus elliottii onde a redución do aumento de volume sen casca foi do 14,99 \% e o da altura total do 12,02 \% (Figueiredo F. A., 1991). Porén, o que quedou demostrado é que canto maior é a produción de mera menor son os crecementos diamétricos das árbores (Palma, 2007).

A última experiencia da que se ten coñecemento en Galicia, é a que propón o IFIE en 1970 titulada "Estudo da resinación en Galicia mediante o sistema de pica de casca con estimulante sólidos, sobre caras anchas", onde se pretendía realizar un estudo sistemático da resinación a base do sistema de pica de casca con estimulante sólido executado sobre caras de anchura superior á normal en España, establecida en $12 \mathrm{~cm}$, propoñendo o estudo contrastar, durante 5 anos (1971-1975) a resinación sobre caras de $20 \mathrm{~cm}, 16 \mathrm{~cm}$ e $12 \mathrm{~cm}$ (referencia) e distintos sistemas de recollida en función da anchura e da compatibilidade co aproveitamento madeireiro, realizando, así mesmo, un control da perda de crecemento debido á resinación.

Practicamente quizabes foron as últimas experiencias, agás da proposta do ano 1970 para realizar a experiencia nos montes de Alto de Sobrada da parroquia de Sobrada e o monte Cabritas da parroquia de Currás, ámbolos dous no concello de Tomiño.

\section{DISCUSIÓN}

En primeiro lugar o máis destacable desta revisión son as numerosas experiencias e ensaios de resinación que se realizaron en Galicia entre a década dos 50 e os 60, e o pouco coñecidos que son tanto no ámbito forestal galego como nacional. Malia que estes ensaios foron numerosos, é verdade que estiveron bastante localizados na provincia de Pontevedra, quedando fóra outras localizacións xeográficas, como o centro e sur da provincia de Ourense, que pola súa climatoloxía e xeografía (temperatura, precipitacións, humidade relativa; exposición, etc.) poderían ter máis interese para a produción de mera; todo iso se cadra motivado pola falta de masas de Pinus pinaster Ait. de dimensións suficientes.

É destacable entre todas as experiencias, a realizada pola Deputación de Pontevedra no Morrazo (Pontevedra) pola súa magnitude, tanto no tempo, 5 anos, como no número de 
piñeiros resinados, 22.000 pés. Esta importante experiencia e as outras realizadas que no seu conxunto superaron de media os $2 \mathrm{Kg} /$ árbol, son representativas das posibles producións que poderían obterse en Galicia por árbore e campaña de resinación; valores que se consideran dentro do grao da produtividade do Pinus pinaster, que oscila entre 2 e 3 kg/ árbol de media (Picardo, 2013).

Outra cuestión destacable é a preocupación, dende os primeiros ensaios, do efecto que a resinación tería na perda de crecemento das árbores, e, en definitiva, no volume madeirable; aínda que pouco ou nada se descubriu da perturbación que o método resinación proposto ( 2 ou 5 anos antes da corta) podería ter tamén na calidade da madeira. Hoxe é un feito constatable que a modalidade de resinación a vida é dificilmente compatible co aproveitamento da madeira para serra, porén, a modalidade a morte, permitiría a consecución de madeira de calidade e a obtención de resina, como produto secundario (Anastácio et al, 2008).

Nas dúas décadas de ensaios que se realizaron en Galicia, os sistemas de resinación empregados foron evolucionando ata o sistema de pica de casca con estimulación con pasta química, que ao final chegouse a instaurar no resto da península ibérica ata a actualidade, e que non se consolidou en Galicia pola falta de tradición resineira e tamén pola chegada da crise nos prezos da mera. Circunstancia de gran trascendencia xa que este método implica unha serie de vantaxes sobre os outros sistemas: a compatibilidade do aproveitamento resineiro e madeireiro, a maior produtividad, e a maior facilidade de aprendizaxe (Hernández, 2006).

\section{CONCLUSIÓNS}

1. O antiguo IFIE mantivo líñas de experiencias durante alomenos dúas décadas en Galicia para atopar un método de resinación complementario ao aproveitamento principal ou madeireiro, limitándoo como máximo aos dous ou cinco anos previos á corta final, sen chegar a propoñer a resinación como aproveitamento principal.

2. As experiencias demostraron a superioridade do sistema de resinación de pica de casca con estimulación de pasta química, establecéndose unha produtividade mínima de 2 $\mathrm{kg} /$ talladura para resinación nos anos previos á corta das árbores. Aportáronse solucións aos factores naturais que máis poden influír na produción de resinas en Galicia, como son os climáticos (precipitacións, temperaturas, etc.), e os silvícolas (densidade, diámetro normal, biomasa, etc.).

3. Aínda que se tratan de experiencias que pouco aportan xa de interese sobre os factores tecnolóxicos como son os sistemas de resinación ou os estimulantes, os resultados sobre a intensidade, época de resinación ou producións constitúen unha base de interese no escenario actual de interese renovado pola resinación en Galicia.

4. As decisións sobre a viabilidade da resinación en Galicia deberían considerar tanto a cantidade como a calidade da mera que se poida producir, así como o desenvolvemento de métodos e sistemas de resinación adaptados ás características do medio forestal galego.

\section{BIBLIOGRAFÍA}

ANALES DEL IFIE, 1962. Informe sobre las experiencias de producción de miera por los nuevos sistemas de resinación", por la Sección de resinas y productos derivados del IFIE., n. 7, p.177-211. 
ANALES DEL IFIE, 1965. Informe sobre las experiencias de producción de miera por los nuevos sistemas de resinación", por la Sección de resinas y productos derivados del IFIE., n. 7, p.177-211.

ANASTÁCIO, D.; CARVALHO, J. 2008. Sector dos resinosos em Portugal. Evolução e análise. DGRF

BLANCO ASENSIO S. 2011. La resinación por el método de pica de corteza ascendente. Estudio de tiempos, rendimientos y costes en distintos montes de la provincia de Segovia http:/ / oa.upm.es/ 7099/

CALDERÓN, A. 2009. Industrias y productos forestales. Cuadernos de dasonomía Serie Didáctica № 14 Departamento de Producción Agropecuaria Facultad de Ciencias Agrarias. Universidad Nacional de Cuyo

FIGUEIREDO FILHO, A., 1991. Influência da Resinagem no Crescimento de Pinus elliottii var. elliottii e sua Avaliação Econômica. Universidade Federal do Paraná, Doutoramento

GARCÍA BORREGÓN R. 1966 Carta del ingeniero Jefe del Distrito Forestal de Pontevedra a Miguel Gaviña Mújica sobre el "Informe influencia de la resinación en relación con el aprovechamiento de la madera realizado por la Sección de Resinas del IFIE. Documento inédito de la biblioteca del CIF de Lourizán

GOMES, A.M.A., 1954. Sobre a influência da resinagem no crescimento do Pinheiro bravo I - Crescimento em diâmetro. Ministério da Economia, DGSFA. Estudos e Informação no 43E3, Lisboa.

GUARDIA, N., 1998. Repercusiones socioeconomicas de la resinacion en montes privados. In 1 er Simposio de Aprovechamiento de Resinas Naturales. Segovia, 5-7 de Fevereiro.

HERNÁNDEZ MUÑOZ, L. 2006. El antiguo oficio de resinero. Ministerio de Agricultura, Pesca y Alimentación. 2006. Hoja divulgativas no 2116. 31 págs. ISBN, 84-491-0687-7.

IFIE. Sección de resinas y productos derivados, 1961 "Informe sobre la resinación de los pinares de Galicia y condiciones generales que se proponen para la concesión de este aprovechamiento". 1961. Documento inédito del IFIE-biblioteca Lourizán.

IFIE. Sección de resinas y productos derivados, 1967 "Estudio relativo a la influencia que ejerce la resinación, por el sistema de pica de corteza con estimulación, en el crecimiento maderable". 1967. Documento inédito del IFIE- biblioteca Lourizán.

IFIE. Sección de resinas y productos derivados, 1970 "Propuesta general sobre el estudio de la resinación en Galicia mediante el sistema de pica de corteza con estimulante sólidos, sobre caras anchas". . Documento inédito del IFIE- biblioteca Lourizán.

NÁJERA, F. et al 1956. Experiencias de producción de miera. Sección de resinas y productos derivados. 1956. Anales del instituto forestal de investigaciones y experiencias, n.1, p. 103-112.

NÁJERA, F. et al 1957. Técnicas Modernas en la resinación de los pinos españoles. Sistema de espina de pescado con cepillo Mazek. Sección de resinas y productos derivados. 1957. Anales del instituto forestal de investigaciones y experiencias, n.2, p. 125-141.

NÁJERA, F. 1957 “Informe sobre la posible resinación de los pinares de Galicia y estudio de las bases generales que deberá cumplir este aprovechamiento". 1957. Documento inédito de la biblioteca del CIF de Lourizán.

Palma, A.M.V., 2007. Capacidade produtiva de resina do pinheiro bravo: Breve panorâmica do sector resineiro em Portugal, Trabalho apresentado como dissertação original para efeitos de acesso à categoria de Investigador Auxiliar, Oeiras: Instituto Nacional de Recursos Biológicos - Estação Florestal Nacional 
PICARDO NIETO, A. 2013. La resinación en España y en el mundo en 2013: Situación y perspectivas. Actas del II Simposio Internacional. de Resinas. Naturales. II Coca Segovia 16 al 18 de abril de 2013 http://4.interreg-sudoe.eu/ contenido-dinamico/ libreriaficheros/ 08245976-7B8C-2E71-B891-FDAEB7077CF8.pdf

PINILLOS et al., 2004 La resina: Herramienta de conservación de nuestros pinares, basada en el contenido del informe diagnóstico y propuestas de actuación en el sector resinero

RADICH, M.C., 1995. O saber da resinagem em Portugal. Ler História 27/ 28:177-199.

RODRÍGUEZ SOALLEIRO, R., Serrada, R., Lucas, J.A., Alejano, R., Del Río, M., Torres, E., Cantero, A., 2008. Selvicultura de Pinus pinaster Ait. subsp. mesogeensis Fiéis \& Gaussen. En: Serrada, R., Montero, G., Reque, J.A. (Eds.), Compendio de selvicultura aplicada en España. INIA, 399-430

SANTOS, CRISTINA 2013 Resinagem em Portugal. Situação Atual e Perspetivas Futurashttp:/ / www.sust-forest.eu/ sites/ www.sust-forest.eu/ files/ cristina_santos.pdf

SERRADA, R, 2004. Apuntes de selvicultura. Fundación Conde del valle de Salazar. E.U.I.T. Forestal, Madrid

SOLÍS, W. 1968. "Experiencias de resinación con el sistema de espina de pescado con el cepillo Mazek sobre Pinus pinea”. Comunicaciones del IFIE n. 2, 10 p.

Revista Galega de Economía: http:/ / www.usc.es/ econo/ RGE/ benvidag.htm https://ideas.repec.org.s/ sdo/ regaec.html 